\title{
Baudelaire, Lettres à sa mère
}

\section{Andrea Schellino}

\section{(2) OpenEdition}

\section{Journals}

\section{Édition électronique}

URL : http://journals.openedition.org/studifrancesi/10694

DOI : 10.4000/studifrancesi. 10694

ISSN : 2427-5856

\section{Éditeur}

Rosenberg \& Sellier

\section{Édition imprimée}

Date de publication : 1 décembre 2017

Pagination : 572

ISSN : 0039-2944

\section{Référence électronique}

Andrea Schellino, "Baudelaire, Lettres à sa mère », Studi Francesi [En ligne], 183 (LXI | III) | 2017, mis en ligne le 01 février 2018, consulté le 21 janvier 2021. URL : http://journals.openedition.org/ studifrancesi/10694; DOI : https://doi.org/10.4000/studifrancesi.10694

\section{Ce document a été généré automatiquement le 21 janvier 2021.}

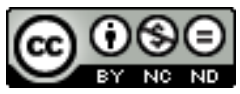

Studi Francesi è distribuita con Licenza Creative Commons Attribuzione - Non commerciale - Non opere derivate 4.0 Internazionale. 


\title{
Baudelaire, Lettres à sa mère
}

\author{
Andrea Schellino
}

\section{RÉFÉRENCE}

CHARLES BAUDELAIRE, Lettres à sa mère, correspondance établie, présentée et annotée par C. Delons, Paris, Manucius, 2017, «Littéra», 480 pp.

1 La correspondance de Baudelaire avec sa mère - tout lecteur du poète le sait bien n'est pas une correspondance parmi d'autres. Elle est l'une des correspondances, sinon l'une des «œuvres» les plus belles que le XIx ${ }^{e}$ siècle nous a laissées, même si $\mathrm{M}^{\mathrm{me}}$ Aupick reste pour nous presque muette, ses lettres ne nous étant pas parvenues. «Suspendu aux réactions maternelles» (p.11), Baudelaire s'est entièrement dévoilé à sa mère. Il ne lui a caché aucune amertume, aucune déception, aucune ambition frustrée. Elle est pour lui l'objet d'un amour confinant à la vénération et d'une violence évoquant tous les extrêmes: «j'ai peur de te tuer, de détruire ton faible corps. [...] Et cependant, dans les circonstances terribles où je suis placé, je suis convaincu que l'un de nous deux tuera l'autre, et que finalement nous nous tuerons réciproquement. Après ma mort, tu ne vivras plus, c'est clair. Je suis le seul objet qui te fasse vivre», écrit Baudelaire à sa mère le 6 mai 1861.

Dans la belle préface à sa réédition de cette correspondance, Catherine Delons rappelle cette relation déchirante: «Horizon fermé ou lueur d'esprit, déversant, sur son malêtre, des "paquets d'horreur" (29 mars 1861) ou le baume d'une douceur apitoyée, Caroline Aupick hanta le cœur et l'esprit de son fils» (p. 11). Elle évoque également, et à juste titre, la manière avec laquelle Baudelaire «accepte, et même revendique, une dépendance, matérielle et affective, vis-à-vis de sa mère» (p.13), alors qu'il regrette, toute sa vie durant, l'opprobre de sa tutelle judiciaire. Connue grâce à ses biographies de Narcisse Ancelle (Narcisse Ancelle, persécuteur ou protecteur de Baudelaire, Tusson, Du Lérot, 2002) et de $\mathrm{M}^{\mathrm{me}}$ Aupick (L'Idée si douce d'une mère. Charles Baudelaire et Caroline Aupick, Paris, Les Belles Lettres, 2011), Catherine Delons était assurément la baudelairienne la mieux placée pour éditer les lettres de Baudelaire à sa mère. 
Échouées à Félicité Ducessois, demi-belle-sœur du poète, après la mort de $\mathrm{M}^{\mathrm{me}}$ Aupick, ces lettres franchirent inédites le cap du siècle, à l'exception de celle datée du 18 novembre 1858. Ce n'est qu'en 1917, cinquantenaire de la mort de Baudelaire, que, dans La Revue de Paris, sont publiées cent trente lettres à $\mathrm{M}^{\mathrm{me}}$ Aupick. Neuf ans plus tard, Jacques Crépet faisait paraître les Dernières lettres inédites à sa mère, comprenant cent dix-huit lettres ou fragments complétant la correspondance précédemment publiée. Les lettres données dans ces recueils, ainsi que quelques publications occasionnelles, ont été recueillies par Jacques Crépet, avec quarante-deux lettres supplémentaires, dans la Correspondance générale de Baudelaire, éditée entre 1947 et 1953 chez Louis Conard. Dans leur édition chez la Bibliothèque de la Pléiade, en 1973, Claude Pichois et Jean Ziegler ont intégré ce corpus avec les lettres inédites publiées en 1966 par Philippe Auserve, chez Grasset.

3 Même si l'édition de Catherine Delons n'apporte aucune lettre inédite de Baudelaire à $\mathrm{M}^{\text {me }}$ Aupick, elle donne néanmoins trente-trois documents pour la plupart inconnus, dont des lettres de Narcisse Ancelle à $\mathrm{M}^{\mathrm{me}}$ Aupick, et des lettres de $\mathrm{M}^{\mathrm{me}}$ Aupick à Narcisse Ancelle et à Alphonse Baudelaire. En outre, le texte de plusieurs des trois cent cinquante lettres de Baudelaire à sa mère a été revu d'après les manuscrits originaux ou leur copie. L'annotation des lettres, bien que restreinte, permet de suivre aisément le déroulement de la correspondance. 